\section{Anti-bacterial therapy}

The Battle Against Bacteria: A Fresh Look. By P. Baldry. Pp. 179. (Cambridge University: Cambridge, London, New York and Melbourne, 1976). £4.50.

ONLY six of the 15 groups of antibacterial drugs now in wide use were available 20 years ago. Since then, however, the spectre of transferable drug resistance has become the constant adversary of microbiologist and clinician alike. These dramatic changes are emphasised by even a superficial comparison of the two editions of Dr Peter Baldry's history of anti-bacterial therapy. The first edition, although published in 1965, took the story only up to the late 1950s and occupied a compact 100 pages. Inevitably its successor is over $70 \%$ longer. It describes the evolution of a field which is a fascinating meeting ground of microbiology, clinical medicine, biochemistry, pharmacology and molecular biology.

The book is least successful when summarising the history of bacteriology as distinct from therapy. Thus Leeuwenhoek did not see the 'animalcules' which cause disease; he saw only saprophytes and normal commensals. His illustrious predecessor Robert Hooke is not mentioned, even though an engraving from Hooke's Micrographia is included (without attribution). Joseph Lister's pioneering bacteriological work--which included isolating the first pure bacterial cultures -also goes unnoticed, as does his even

\section{Noradrenaline and adrenergic nerves}

Peripheral Sympathetic Neurotransmission. By W. De. Potter. Pp. xv +161. (Arscia Uitgaven, NV: Brussels, 1976.)

THIS book is a strongly personal account of the longstanding research interests of the author and his laboratory. Since he is an acknowledged leader in his field, it is predictably a good account of the biochemical aspects of the synthesis, storage and release of noradrenaline from adrenergic nerves. Factors affecting the storage and release, such as electrical stimulation, and $\alpha$ - and $\beta$-receptorblocking agents, are also described. The relationship between the different noradrenaline-containing particles is discussed. There is a clear and informative diagram at the end of the book which summarises the author's views of the origin and fate of nor- more relevant observation of 1871 on the antibiotic action of Penicillium cultures. Moreover, Lister was not Professor of Surgery at Edinburgh but in Glasgow at the time of his original discovery of antisepsis. The romantic legend of the martyrdom of Semmelweiss also needs correction. This tragic pioneer of hand disinfection in obstetrics in fact suffered from chronic paranoia. After increasing insanity necessitated his commital to a mental hospital his death from presumed streptococcal septicaemia-following a hand injury -was supreme irony. For this was the infection he had prevented in thousands of women during childbirth.

The author is on much firmer ground with his main theme-the discoveries of anti-bacterial drugs. There are only two major disappointments here-apart from the lack of any references: the story of the British work on sulphonamides (culminating in M\&B 693) is omitted, and the central chapter on Fleming's original observations of 1928 remains unchanged from the first edition. There is no mention of the fascinating revelations published in 1970 by Fleming's colleague, Ronald Hare. In his book The Birth of Penicillin, Hare showed that almost every detail of the familiar story is erroneous. Nevertheless, Dr Baldry's book is a good introduction to an enthralling subject. It should attract a wide audience.

Sydney Selwyn

Sydney Selwyn is Reader in Medical Microbiology at Westminster Medical School, London, UK.

adrenaline storage particles. The sections on methods are especially good and should be most useful to those engaged in this area of research. The bibliography is fairly extensive (270 references) although it stops at 1973.

My one reservation is related to the title. In my opinion, this title implies a general coverage of all aspects of transmission including information on neuroeffector geometry, the electrophysiology of transmission, and effector cells including 'receptor' characteristics. These topics are not discussed. There is also little account of transmitter inactivation mechanisms. I have, however, no hesitation in recommending this book for its lucid description of storage and release of noradrenaline from sympathetic nerves. It would make a useful addition to the library of anyone working in the field of neurotransmission.

G. Burnstock

G. Burnstock is Head of the Department of Anatomy and Embryology at University College, London, UK.

\section{Electric fields and isolated atoms}

Atoms and Molecules in Electric Fields. By N. Ryde. Pp. 455. (Almquist and Wiksell International: Stockholm, 1976.)

THE effect of external electric fields on the spectra of isolated atoms and simple molecules has been investigated since early this century. In particular the splitting and shifts in spectral lines observed as the external field is increased, resulting from the perturbation of otherwise spatially degenerate levels, have been important in the development of quantum theory. These 'Stark effect' measurements continue to provide important information on oscillator strengths and the assignment of spectra. Increasingly though, interest has shifted to the application of these effects, for example, in astrophysics or plasma studies where the broadening or line shift can be related to the electron density and temperature. There is thus a need, identified by the author, for a critical compilation of the large amount of data amassed in the past forty years for use in these new areas.

The most substantial and useful section of this book forming about $50 \%$ of the whole is just such a compilation of the experimental or calculated electric field properties of some fifty atoms and atomic ions, much of this work dating from the 1920-1930s. Spectral assignments are discussed and plots of line displacement with field strength are recorded here. A large part of the remainder of the book is concerned with the quantum theory of these processes. This section begins with a detailed account of elementary perturbation theory and then reviews the application and development of these techniques in a wide range of atomic and molecular situations.

The other chapters in the book dealing with experimental matters and molecular species are rather limited in scope and will be of only limited interest to the type of reader for whom this book is intended. The use of the phrase 'canal ways' throughout the book makes a curious impression. There is no index.

This book will be a useful reference for those using the atomic 'Stark effect'.

Malcolm Fluendy

Malcolm Fluendy is Lecturer in the Department of Chemistry, University of Edinburgh, UK. 